\title{
Studying ZIF-8 SURMOF Thin Films with a Langatate Crystal Microbalance: Single-Component Gas Adsorption Isotherms Measured at Elevated Temperatures and Pressures
}

\author{
Elvia P. Valadez Sánchez, Alexander Knebel, Luis Izquierdo Sánchez, Michael Klumpp, Christof Wöll, \\ and Roland Dittmeyer*
}

\begin{abstract}
Characterizing the adsorption behavior of thin films at technical operation ranges is highly relevant in order to obtain appropriate experimental parameters, as well as to evaluate their possible integration in multiple applications. Nonetheless, gathering such experimental data is not a trivial task. In the case of metal-organic framework thin films, a particular interesting class of highly porous coatings, determination of adsorption isotherms at elevated temperatures and pressures is not commonly reported. Using a custom designed langatate crystal microbalance following the principle for piezoelectric microbalances, but under harsher conditions, allowed us to present adsorption equilibrium
\end{abstract} measurements on a zeolitic imidazolate framework 8 (ZIF 8)
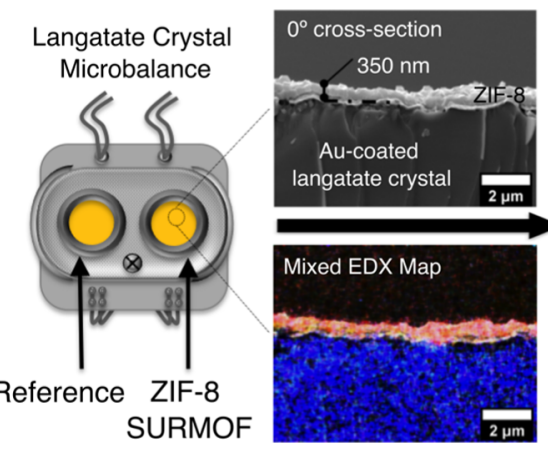

Adsorption isotherms Alkanes and Alkenes

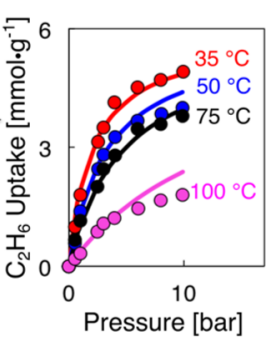
surface mounted metal-organic framework (SURMOF) thin film at temperatures between 35 and $100{ }^{\circ} \mathrm{C}$ and at a pressure range up to 10 bars. The layer by layer liquid phase epitaxy approach was used to deposit ZIF 8 SURMOF thin films on langatate crystals. X ray diffraction, infrared reflection absorption spectroscopy, and scanning electron microscopy combined with energy dispersive $\mathrm{X}$ ray mapping were used to gather deeper information on the ZIF 8 thin film growth. Single component isotherms were collected for different gases of practical interest, that is, $\mathrm{CO}_{2}, \mathrm{C}_{2} \mathrm{H}_{6}, \mathrm{C}_{2} \mathrm{H}_{4}, \mathrm{C}_{3} \mathrm{H}_{8}$, and $\mathrm{C}_{3} \mathrm{H}_{6}$. The measurements were obtained at $35,50,75$, and $100{ }^{\circ} \mathrm{C}$ at a gauge pressure range up to 10 bars. The collected data showed a clear preferential adsorption of ethane over ethylene, whereas only a slight difference was found between propane and propylene. Additionally, the experimental data allowed for the determination of adsorption equilibrium constants and saturation loadings of the ZIF 8 material as a thin SURMOF film, which is of great importance for its integration in multiple applications, such as sensor devices or in membrane based separation.

\section{INTRODUCTION}

Surface mounted metal-organic frameworks (SURMOFs) are porous materials typically of thin, highly oriented, and crystalline nature. They possess several advantages over conventional metal-organic framework (MOF) films includ ing controllable thicknesses, smoother morphologies, and lower defect densities. ${ }^{1}$ Therefore, SURMOF thin films are particularly attractive and suitable for integration in diverse processes and devices, requiring high quality surfaces without the presence of pinholes or cracks, ${ }^{2}$ for example, for sensing applications and membrane based separation. ${ }^{3-5}$ When considering such applications, obtaining quantitative informa tion on their sorption behavior as well as the characteristics of the material within a technical operation range is crucial to truly assess its potential. Quartz crystal microbalances are commonly employed to study the adsorption behavior of microporous sorbents, such as MOFs, gravimetrically. None theless, quartz crystals have a known temperature limit close to $80{ }^{\circ} \mathrm{C}$. ${ }^{6}$ Langatate crystals resemble quartz but offer a broader temperature range of operation, permitting the study of a material's adsorption properties at higher temperatures. ${ }^{7}$ A recent work succeeded in the study of the adsorption behavior of zeolite ZSM 5 using a crystal microbalance adapted for langatate crystals. ${ }^{8}$ This proved the possibility of measuring and analyzing gas adsorption under harsher conditions.

Zeolitic imidazolate framework 8 (ZIF 8) is a highly known and explored MOF material belonging to the ZIF subclass. Its considerable thermal and mechanical stabilities, as well as its narrow sized windows of around $3.4 \AA{ }^{9}$, have made it a very interesting candidate for diverse applications, including gas 
separation and heterogeneous catalysis. ${ }^{10}$ For example, the exploration of alkane/alkene separation has been a focal point of study in various works, particularly given the similarity of the size of the windows with the kinetic diameters of short hydrocarbons. ${ }^{11-13}$ To apply ZIF 8 in gas separation membranes, investigating its adsorption behavior at technical operation ranges is highly interesting. For instance, for ethylene/ethane and propylene/propane membrane splitters, typical operating temperatures and pressures vary from 30 to $100{ }^{\circ} \mathrm{C}$ and between 3 and 10 bar, respectively. ${ }^{14}$ Looking at $\mathrm{CO}_{2}$ capture from point sources via membranes, for example, for utilization as a chemical feedstock, for storage, or for sequestration, often operation temperatures of $100{ }^{\circ} \mathrm{C}$ or above are required at different pressures ${ }^{15}$ in order to obtain attractive fluxes.

Nonetheless, in general, not much information about the adsorption behavior of MOF materials at high temperatures has been reported, particularly when speaking about thin films. As a matter of fact, to the best of our knowledge, the experimental determination of ZIF 8's gas adsorption behavior under both high temperatures and pressures has not yet been reported in the literature. In this work, we explore the high pressure and high temperature gas adsorption on a ZIF 8 SURMOF film for $\mathrm{CO}_{2}, \mathrm{C}_{2} \mathrm{H}_{6}, \mathrm{C}_{2} \mathrm{H}_{4}, \mathrm{C}_{3} \mathrm{H}_{8}$, and $\mathrm{C}_{3} \mathrm{H}_{6}$ using a crystal microbalance adapted for langatate crystals (see Figure 1). The adsorption isotherms were obtained at $35,50,75$, and

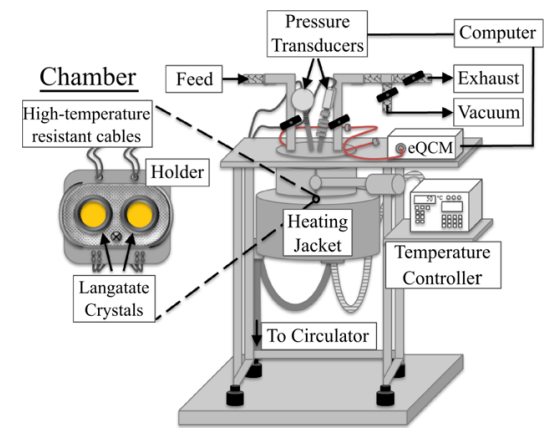

Figure 1. Schematic of the custom designed LCM for high temperature and high pressure adsorption measurements.

$100{ }^{\circ} \mathrm{C}$. The data collected were fitted to the Langmuir model in order to determine the adsorption equilibrium constants, saturation loadings, and heats of adsorption for the ZIF 8 material in a film at different temperatures. Such data are fundamental for a valid prediction of the performance of the ZIF 8 SURMOF thin films in multiple applications based on detailed simulation models.

\section{EXPERIMENTAL SECTION}

2.1. ZIF-8 SURMOF Synthesis. The ZIF 8 SURMOF was synthesized on a langatate crystal sensor (C3 Prozess und Analysentechnik $\mathrm{GmbH}$, Munich, Germany) with a diameter of 14 $\mathrm{mm}$, a finely lapped surface, $\mathrm{Ti}-\mathrm{Au}$ electrodes, and a resonant frequency of $5 \mathrm{MHz}$. The crystal was initially cleaned in deionized water by ultrasonication for $5 \mathrm{~min}$ and then dried at $80^{\circ} \mathrm{C}$ for $10 \mathrm{~min}$. Afterward, the crystal was immersed in a $1 \mathrm{mM}$ ethanolic solution of 11 mercapto 1 undecanol (Sigma Aldrich) for $24 \mathrm{~h}$, in order to create a self assembled monolayer (SAM) with a hydroxide functionalized surface. Next, the crystal was rinsed with $\mathrm{EtOH}$, dried with $\mathrm{N}_{2}$, and placed in the appropriate holder to begin with the ZIF 8 SURMOF synthesis.
Following the layer by layer (LBL) liquid phase epitaxy approach, the thin film was deposited using a MSM Robust carousel tissue stainer device (Slee Thomas Medical, Austria); see Supporting Information Figure S1. Following the same synthesis routes as in previous studies, ${ }^{16,17}$ the crystal was then sequentially immersed for 175 deposition cycles. Each cycle consisted of 4 dipping steps in methanolic solutions as follows: (1) $300 \mathrm{~s}$ in $10 \mathrm{mM}$ zinc nitrate hexahydrate $98 \%$ (Alfa Aesar), (2) $100 \mathrm{~s}$ in $\mathrm{MeOH}$ (Merck SeccoSolv), (3) $300 \mathrm{~s}$ in $20 \mathrm{mM} 2$ methyl $1 \mathrm{H}$ imidazole (Merck), and (4) $100 \mathrm{~s}$ in $\mathrm{MeOH}$ (Merck SeccoSolv). After the completion of all the cycles, the sample was left inside the hood for drying.

The sample was then characterized with $\mathrm{X}$ ray diffraction (XRD) and infrared reflection absorption spectroscopy (IRRAS). For the XRD measurements, a D8 Advance diffractometer (Bruker) equipped with a Si strip detector (PSD Lynxeye) in $\theta-\theta$ geometry and variable divergence slit on the primary side applying $\mathrm{Cu} \mathrm{K} \alpha_{1,2}$ radiation with a wavelength of $0.15419 \mathrm{~nm}$ was employed. The measurements were recorded using a step width of $2 \theta=0.02^{\circ}$ and $84 \mathrm{~s}$ per step over an angular range of $2 \theta=5.5-20^{\circ}$. The IRRA spectra were recorded under ambient conditions using a Vertex 80 FTIR spectrometer (Bruker Optics) equipped with a liquid nitrogen cooled mercury cadmium telluride narrow band detector and a grazing incidence sample accessory providing an angle of $80^{\circ}$ relative to the surface normal. The background measurements were performed using perdeuterated hexadecanethiol SAMs on gold coated silicon wafers.

Scanning electron microscopy (SEM) and energy dispersive $\mathrm{X}$ ray spectroscopy and mapping (EDXS, EDXM) were carried out using a TESCAN Vega 3 with a heated tungsten filament electron source and a Bruker XFlash 610M EDX detector. All images were made with 10 $\mathrm{kV}$ emission voltage with 8-10 $\mu \mathrm{A}$ emission current at a $14 \mathrm{~mm}$ working distance. For EDXM, the accumulation time was $30 \mathrm{~min}$. To get the cross section, the sample was simply broken and glued to the cross section holder using conductive carbon glue tabs. Before the measurement, the sample was sputtered with a BalTec MCS 010 coating system with a sub nanometer coating of $\mathrm{Au}-\mathrm{Pd}$ to reduce charging effects.

2.2. Langatate Crystal Microbalance. All adsorption measure ments were done using a custom designed langatate crystal holder inside of a $100 \mathrm{~mL}$ high pressure stainless steel chamber (Büchi AG, Uster, Switzerland) connected with high temperature resistant cables to a commercial frequency oscillating electrochemical quartz crystal microbalance $10 \mathrm{M}$ (Gamry Instruments, Warminster, USA). This measurement system was already developed and validated in a previous work investigating the gas adsorption in zeolite H ZSM 5., ${ }^{8,18}$ As it can be seen in Figure 1, the device holds two langatate crystals, one serving as the reference and the other as the sample. The pressure and temperature limits of the chamber are $300 \mathrm{bar}$ and $275{ }^{\circ} \mathrm{C}$, respectively; the latter is defined by the maximum operating temperature of the $\mathrm{O}$ rings (Kalrez 6375) which ensure a sealed chamber at high pressures. The pressure in the system is regulated by two different pressure transducers of $0-1$ bar absolute (Haenni) and 0-60 bar gauge (WIKA, Klingenberg, Germany). The temperature in the system is set with a btc 01 temperature controller (Büchi AG, Uster, Switzerland) connected to thermocouples close to the crystals. During the experiments conducted, the temperature regulator reached precisions of $\pm 0.1{ }^{\circ} \mathrm{C}$ at $35^{\circ} \mathrm{C}, \pm 0.25{ }^{\circ} \mathrm{C}$ at $50{ }^{\circ} \mathrm{C}, \pm 0.35{ }^{\circ} \mathrm{C}$ at 75 ${ }^{\circ} \mathrm{C}$, and $\pm 0.4{ }^{\circ} \mathrm{C}$ at $100{ }^{\circ} \mathrm{C}$.

2.3. Reference Measurements. The device holds two crystals. One is the neat crystal and serves as a reference, while the other one is the ZIF 8 coated crystal, that is, the sample. Before beginning with adsorption measurements and prior to any synthesis, bothuncoated-crystals were placed in the holder, the chamber was then closed gas tight, evacuated, and purged with $\mathrm{N}_{2}$ three times. The crystals were then activated overnight under vacuum at $75{ }^{\circ} \mathrm{C}$. Following, the resonant frequencies of the two-uncoated-crystals were recorded for $35,50,75$, and $100{ }^{\circ} \mathrm{C}$ over a gauge pressure range between 0 and $10 \mathrm{bar}$. These pressures were adjusted by introducing $\mathrm{N}_{2}$ via a mass flow controller into the chamber. This step is of great importance because there are always variations between different langatate crystals, which cause a frequency difference, $\Delta f_{\mathrm{r}}$. This 
difference must be defined prior to film deposition for all parameter sets - in terms of temperature and pressure - to be investigated. This will permit, later on, the accurate determination of the adsorbed mass. In addition, these reference measurements are also important for being able to account for the dependency of the resonant frequency on temperature and pressure. ${ }^{8}$ The frequency difference is then given

$$
\Delta f_{\mathrm{r}}=f_{1, \mathrm{r}}-f_{2, \mathrm{r}}
$$

where $f_{1, \mathrm{r}}$ is the resonant frequency of the first "uncoated" crystal, and $f_{2, \mathrm{r}}$ is the resonant frequency of the second "uncoated" crystal before adsorption measurements.

2.4. Gas Uptake Measurements. After the reference measure ments, one of the crystals was removed from the holder and treated as specified above in the ZIF 82.1 section. After the synthesis of the ZIF 8 SURMOF was confirmed (see Figure 2), the "coated" crystal or sample was placed once again in the holder. Likewise, the chamber was then closed gas tight, evacuated, and purged with $\mathrm{N}_{2}$ three times. The reference crystal and the sample were then activated under vacuum at the first temperature to be measured, that is, $35{ }^{\circ} \mathrm{C}$. Next and before introducing the gas to be studied, an initial measurement, in order to determine the mass of the film on the "coated" crystal, was performed. Afterward, the gas to be measured was dosed to achieve

a)
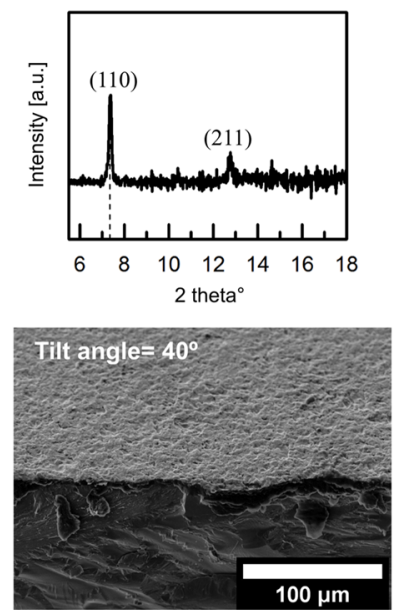

e)

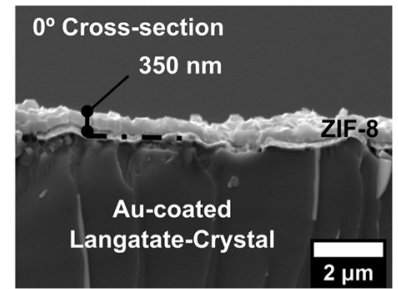

g)
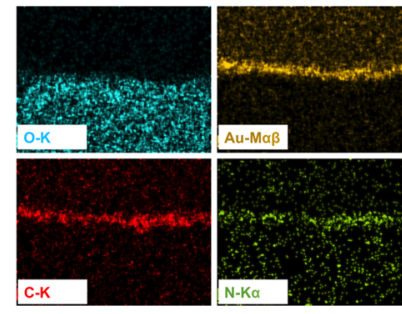

b)
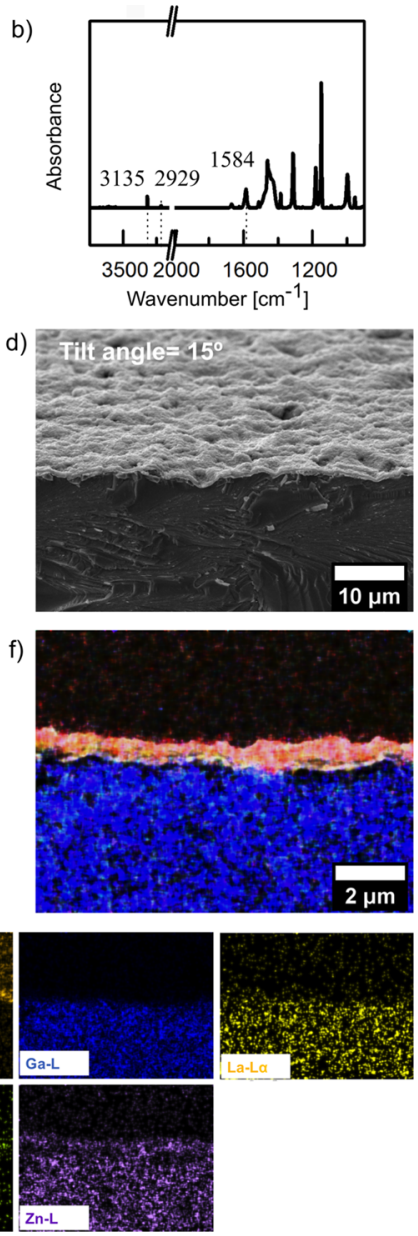

Figure 2. (a) XRD pattern and (b) IRRAS spectra of the ZIF 8 SURMOF sample studied in this work synthesized on a langatate crystal for 175 deposition cycles; cross sectional SEM images of a second ZIF 8 SURMOF sample deposited for 175 cycles on the langatate crystal (c) with $40^{\circ}$ tilt angle and (d) with $15^{\circ}$ tilt angle; (e) high resolution $0^{\circ}$ tilt angle cross section with the $350 \mathrm{~nm}$ ZIF 8 layer; (f) corresponding mixed EDX map; and (g) EDX maps of the elements. each desired pressure point. Once the desired pressure was reached and the temperature was stabilized, the resonant frequencies for the reference and the sample were measured. This was done over a gauge pressure range of $0-10$ bar for $\mathrm{CO}_{2}, \mathrm{C}_{2} \mathrm{H}_{6}$, and $\mathrm{C}_{2} \mathrm{H}_{4}$ and of $0-1.35$ bar for $\mathrm{C}_{3} \mathrm{H}_{8}$ and $\mathrm{C}_{3} \mathrm{H}_{6}$. This exact procedure was then repeated for 50,75 , and $100{ }^{\circ} \mathrm{C}$. Following, the change in frequency, $\Delta f$, was determined by

$$
\Delta f=f_{1}^{*}-f_{2}=f_{1}-\Delta f_{\mathrm{r}}-f_{2}
$$

where $f_{1}^{*}$ is the resonant frequency of the reference, $f_{1}$ is the resonant frequency of the reference during adsorption measurements, and $f_{2}$ is the resonant frequency of the sample during adsorption measure ments.

The shift in frequency is the summation of various independent terms such as temperature, pressure, and viscosity as well as "roughness loading". ${ }^{8,19}$ However, given that both samples were measured together in the same chamber and therefore under the same conditions, such frequency changes were considered negligible. Thus, a shift in frequency in the hereby presented work is solely attributed to changes in mass, that is, $\Delta f=\Delta f_{\mathrm{m}}$. Considering this and using the Sauerbrey equation, ${ }^{20}$ the deposited mass of the ZIF 8 SURMOF on the langatate crystal was first determined.

$$
\Delta m=\frac{n \cdot \Delta f_{\mathrm{m}} \cdot \sqrt{\rho_{1} \cdot \mu_{1}}}{2\left(f_{1}^{*}\right)^{2}} \cdot A
$$

where $\Delta m$ is the difference in mass in grams, $n=3$ is the number of the harmonic driving the langatate crystal, $\rho_{1}=6.13 \mathrm{~g} \cdot \mathrm{cm}^{-3}$ corresponds to the density of the langatate crystal, $\mu_{1}=1.9 \times 10^{12}$ $\mathrm{g} \cdot \mathrm{cm}^{-1} \cdot \mathrm{s}^{-2}$ is the effective piezoelectrically stiffened shear modulus of the langatate crystal, and $A=1.54 \mathrm{~cm}^{2}$ corresponds to the area of the langatate crystal. ${ }^{7,21}$ As explained above, this was the first step before the dosing of every gas. In the present work, the deposited mass of the ZIF 8 SURMOF on the langatate crystal was determined to be 0.049 mg considering the average value of all the measurements at 35-75 ${ }^{\circ} \mathrm{C}$. Likewise, the same formula was then used to determine the gas adsorption for each measurement point.

\section{RESULTS AND DISCUSSION}

As the results from XRD and IRRAS analysis show (cf. Figure $2 \mathrm{a}, \mathrm{b})$, ZIF 8 as the SURMOF was successfully grown on the langatate crystal using the LBL deposition method. In the IRRAS spectrum, the characteristic bands of ZIF 8 in Figure $2 \mathrm{~b}$ could be identified. From the XRD in Figure $2 \mathrm{a}$, good crystallinity of the ZIF 8 SURMOF on the surface could be also observed, considering the fact that the surface roughness of the underlying langatate crystal is high, as distinguishable in the cross sectional overview SEM images of a second sample (cf. Figure $2 \mathrm{c}, \mathrm{d}$ ). The sample is coated very homogenously; however, it was very challenging to find a part of the sample where the high resolution cross sectional image (Figure 2e) showed an almost flat surface. The corresponding EDXM in Figure $2 \mathrm{f}$ and the single element maps in Figure $2 \mathrm{~g}$ give a good idea of the overall structure of the substrate: the langatate crystal shows the elements $\mathrm{Ga}, \mathrm{La}$, and $\mathrm{O}$ in the EDX as expected; Ta was left out of the mixed map because of its low concentration in the sample. In the top layer, attributed to ZIF $8, \mathrm{C}$ and $\mathrm{N}$ from the linker ( 2 methylimidazole) are found. $\mathrm{Zn}$, which is the metal source for the MOF, is found in the whole sample, that is, the langatate crystal contains $\mathrm{Zn}$ too. Still, given that in the Au layer no $\mathrm{Zn}$ is found, the presence of $\mathrm{Zn}$ on the top MOF layer can be affirmed. Furthermore, because of the sputtering process, the $\mathrm{Au}$ signal is found throughout the sample, nevertheless with the highest concentration right below the MOF layer because of the gold coating of the langatate crystal. Overall, the EDXM analysis provided a good 

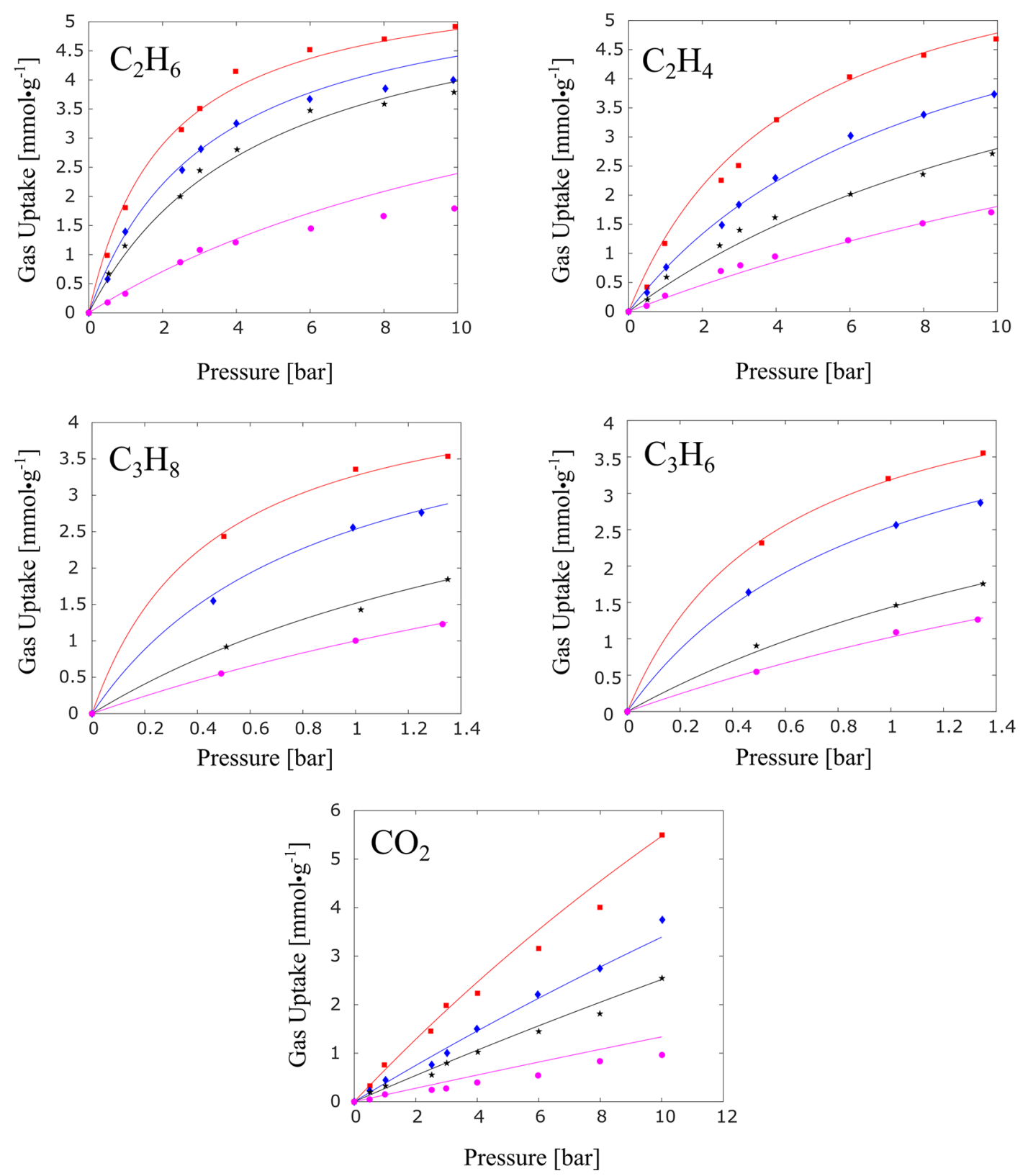

Figure 3. Mean loadings for $\mathrm{C}_{2} \mathrm{H}_{6}, \mathrm{C}_{2} \mathrm{H}_{4}, \mathrm{C}_{3} \mathrm{H}_{8}$, and $\mathrm{C}_{3} \mathrm{H}_{6}$ in the ZIF 8 SURMOF at $35^{\circ} \mathrm{C}$ (red $\left.\boldsymbol{\square}\right), 50{ }^{\circ} \mathrm{C}$ (blue $\bullet$ ), $75^{\circ} \mathrm{C}$ (black $\star$ ), and $100{ }^{\circ} \mathrm{C}$ (pink @) fitted (solid line) to the Langmuir model.

qualitative insight on the ZIF 8 layer, deposited on top of the langatate crystal.

Next, in order to verify the accuracy of the langatate crystal microbalance (LCM) and therefore the reliability of the data deduced, adsorption experiments at $35^{\circ} \mathrm{C}$ were conducted for $\mathrm{CO}_{2}, \mathrm{C}_{2} \mathrm{H}_{6}, \mathrm{C}_{2} \mathrm{H}_{4}, \mathrm{C}_{3} \mathrm{H}_{8}$, and $\mathrm{C}_{3} \mathrm{H}_{6}$. The data obtained is in good agreement with the other published adsorption isotherms for ZIF $8 .^{22-26}$ Considering alkanes and alkenes, these studies (experiments conducted at $20-35{ }^{\circ} \mathrm{C}$ ) report the following ranges at 1 bar: $1-2.5 \mathrm{mmol} / \mathrm{g}^{-1}$ for $\mathrm{C}_{2} \mathrm{H}_{6}, 0.7-1.6 \mathrm{mmol} / \mathrm{g}^{-1}$ for $\mathrm{C}_{2} \mathrm{H}_{4}, 3.6-4.4 \mathrm{mmol} / \mathrm{g}^{-1}$ for $\mathrm{C}_{3} \mathrm{H}_{8}$, and $2.7-4.5 \mathrm{mmol} / \mathrm{g}^{-1}$ for $\mathrm{C}_{3} \mathrm{H}_{6}$. Moreover, molecular simulations and experimental studies have reported that the strongest adsorption sites in ZIF 8 are in the surroundings of the linkers. ${ }^{27-29}$

To continue with the analysis of the adsorption data, mean loadings were determined for all gases from the two replicate measurements; these correspond to the markers shown in
Figure 3. While the adsorption equilibrium constants, $K_{T} ; T=$ $35,50,75$, and $100{ }^{\circ} \mathrm{C}$, are temperature dependent, the saturation loadings, $q_{\text {sat }}$ are theoretically temperature inde pendent for the simple monolayer Langmuir isotherm. ${ }^{30}$ For this reason, the five corresponding Langmuir parameters of each gas, that is, $K_{35^{\circ} \mathrm{C}}, K_{50^{\circ} \mathrm{C}}, K_{75^{\circ} \mathrm{C}}, K_{100^{\circ} \mathrm{C}}$, and $q_{\text {sat }}$, were estimated at the same time with the total data collected, rather than independently for each temperature. Furthermore, the parameters were estimated by minimizing the weighted sum of squares, with the weights being the inverse of the squared standard deviation of each of the corresponding measure ments; in case of no deviation within the measurements, the standard deviation was assumed to be $5 \%$ of the mean loading. For the estimation, the lsqnonlin function of MATLAB was used. Additionally, 95\% likelihood confidence intervals were also determined (see Supporting Information Figure S2, Tables S1-S10). The obtained Langmuir fittings are shown 
in solid lines in Figure 3. When compared to the reported literature, $\mathrm{C}_{2}$ hydrocarbon isotherms have been commonly identified to present a Henry type behavior. ${ }^{26,31}$ Nonetheless, for the pressure and temperature range explored in this work, all single component adsorption isotherms could be generally described with the simple Langmuir model. The corresponding adsorption equilibrium constants and saturation loadings are reported in Table 1 . In general, the obtained saturation

Table 1. Saturation Loadings, $\boldsymbol{q}_{\text {sat }}$, and Adsorption Equilibrium Constants, $K_{T}$, for $\mathrm{C}_{2} \mathrm{H}_{6}, \mathrm{C}_{2} \mathrm{H}_{4}, \mathrm{C}_{3} \mathrm{H}_{8}, \mathrm{C}_{3} \mathrm{H}_{6}$, and $\mathrm{CO}_{2}$ in the ZIF 8 SURMOF at Different Temperatures

$\begin{array}{clccccc}\begin{array}{c}\text { Langmuir } \\ \text { parameters }\end{array} & & \mathrm{C}_{2} \mathrm{H}_{6} & \mathrm{C}_{2} \mathrm{H}_{4} & \mathrm{C}_{3} \mathrm{H}_{8} & \mathrm{C}_{3} \mathrm{H}_{6} & \mathrm{CO}_{2} \\ q_{\text {sat }} & {\left[\mathrm{mmol} \mathrm{g}^{-1}\right]} & 5.87 & 6.88 & 4.76 & 5.01 & 29.47 \\ K_{35^{\circ} \mathrm{C}} & {\left[\mathrm{bar}^{-1}\right]} & 0.48 & 0.23 & 2.19 & 1.75 & 0.02 \\ K_{50^{\circ} \mathrm{C}} & {\left[\mathrm{bar}^{-1}\right]} & 0.30 & 0.12 & 1.14 & 1.03 & 0.01 \\ K_{75^{\circ} \mathrm{C}} & {\left[\mathrm{bar}^{-1}\right]} & 0.21 & 0.07 & 0.47 & 0.4 & 0.009 \\ K_{100^{\circ} \mathrm{C}} & {\left[\mathrm{bar}^{-1}\right]} & 0.07 & 0.04 & 0.27 & 0.26 & 0.005\end{array}$

loadings for the $\mathrm{C}_{2}$ and $\mathrm{C}_{3}$ hydrocarbons are slightly below from what is reported in the literature..$^{22,32,33}$ On the other hand, the saturation loading for $\mathrm{CO}_{2}$ appears to be higher than expected, considering other experimental and simulated studies that have reported $\mathrm{CO}_{2}$ adsorption isotherms $\left(25-35{ }^{\circ} \mathrm{C}\right)$ in ZIF 8 at even higher pressures $(25-30$ bar $){ }^{22,34}$ Future studies should focus on improving further the precision of these estimates, for example, with a larger amount of data, lower standard deviations, and a larger pressure range.

Continuing with the discussion of the data, the amount of adsorbed gas decreased in all the cases with increasing temperatures. Considering only the last mean loading points for each gas and taking $35{ }^{\circ} \mathrm{C}$ as the starting experiment, a decrease in the amount of gas adsorbed of around 22, 43, and $68 \%$ was observed for the 50,75 , and $100{ }^{\circ} \mathrm{C}$ isotherms, respectively.

When comparing the behavior of alkanes and alkenes, it can be observed that the ZIF 8 SURMOF exhibited a preferential alkane adsorption for the $\mathrm{C}_{2}$ hydrocarbons. Considering the difference in the amount adsorbed, the equilibrium selectivity ( $\alpha=K_{\mathrm{C}_{2} \mathrm{H}_{6}} / K_{\mathrm{C}_{2} \mathrm{H}_{4}}$ ) was estimated to be the highest (approx. 3.1) at $75{ }^{\circ} \mathrm{C}$ and lowest (approx. 1.9) at $100{ }^{\circ} \mathrm{C}$. In general, the preferential adsorption of alkanes over alkenes in ZIF 8 has been reported earlier in several studies and identified as a common finding for cation free nonpolar structures; ${ }^{12,23,26}$ such behavior can be attributed to molecular polarizability. ${ }^{26}$ The experiments in this work support once again this observation for thin ZIF 8 films at higher temperatures and pressure regions. In contrast, simulation studies conducted for higher pressures (above $10 \mathrm{bar})^{12,32}$ have shown that further increasing the pressure results in a higher alkene uptake. Wu et al. ${ }^{32}$ explained that such behavior might be related to the smaller size of the alkene, that is, as the pressure continues to rise, the smaller molecule is more capable of accessing the ZIF 8 pores, thus reaching higher uptakes. In the hereby presented work, pressures above 10 bar were not explored; thus, such behavior could not be confirmed.

For the $\mathrm{C}_{3}$ hydrocarbons, that is, for $\mathrm{C}_{3} \mathrm{H}_{8}$ and $\mathrm{C}_{3} \mathrm{H}_{6}$, only a gauge pressure range of up to 1.35 bar was explored. The limitations behind these measurements come from the setup itself, which did not permit to achieve higher pressures for these gases. The adsorption isotherms obtained presented generally the same uptake, that is, very slight differences in adsorption could be observed as the pressure was increased, which agrees with multiple literature data. ${ }^{23,25,33}$ Furthermore, compared to $\mathrm{C}_{2}$ hydrocarbons, not only the relative uptake of $\mathrm{C}_{3}$ hydrocarbons in ZIF 8 was significantly higher in the low pressure region investigated for both species, but also the gradient was larger. Herm et al. ${ }^{35}$ discussed some common trends in MOFs, including that smaller sized alkanes possess lower adsorption strength given their lower molecular surface area for van der Waal interactions. Moreover, in the work by Zhang et al. ${ }^{33}$ adsorption isotherms for $n \mathrm{C}_{4} \mathrm{H}_{10}$ and $1 \mathrm{C}_{4} \mathrm{H}_{8}$ were also reported. The isotherms exhibited extremely similar behaviors and higher uptakes when compared to $\mathrm{C}_{3} \mathrm{H}_{8}$ and $\mathrm{C}_{3} \mathrm{H}_{6}$ at low pressures. Thus, as suggested earlier by Böhme et al., $^{23}$ the interaction strength in ZIF 8 does appear to increase with the hydrocarbon chain length, at least at a low pressure range (below 1 bar). Likewise, Zhang et al. ${ }^{36}$ identified a stronger affinity of the ZIF 8 framework to longer chain hydrocarbons. On the other hand, the preferential adsorption of the alkane over the alkene appears to be reduced with increasing chain length.

Next, the heats of adsorption for the alkanes and alkenes in the ZIF 8 SURMOF were estimated via the van't Hoff equation

$$
K=K_{0} \mathrm{e}^{-\Delta H_{\mathrm{s}} / R T}
$$

where $K_{0}$ is a pre exponential factor, and $H_{\mathrm{s}}$ is the heat of adsorption; ${ }^{26}$ for van't Hoff plots $(\ln K$ vs $1 / T)$ please refer to the Supporting Information Figures S3 and S4. Considering only the Henry type region for the $\mathrm{C}_{2}$ hydrocarbon isotherms, where the guest-host interactions govern sorption, ${ }^{37}$ heats of adsorption of 18.1 and $19.5 \mathrm{~kJ} \cdot \mathrm{mol}^{-1}$ for $\mathrm{C}_{2} \mathrm{H}_{4}$ and $\mathrm{C}_{2} \mathrm{H}_{6}$ were respectively estimated. These values are in line with the literature data ranging between 15 and $20 \mathrm{~kJ} \cdot \mathrm{mol}^{-1} \cdot{ }^{26,31}$ When considering the whole pressure range explored in this work, that is, using $K_{\mathrm{L}}$, higher values $\left(26.5 \mathrm{~kJ} \cdot \mathrm{mol}^{-1}\right.$ for $\mathrm{C}_{2} \mathrm{H}_{4}$ and $26.9 \mathrm{~kJ} \cdot \mathrm{mol}^{-1}$ for $\mathrm{C}_{2} \mathrm{H}_{6}$ ) were obtained. For the $\mathrm{C}_{3}$ hydrocarbons, the heats of adsorption were estimated using the Langmuir constants given the data available. In the case of $\mathrm{C}_{3} \mathrm{H}_{6}$ and $\mathrm{C}_{3} \mathrm{H}_{8}$, the heats of adsorption obtained were of 29.1 and $31.2 \mathrm{~kJ} \cdot \mathrm{mol}^{-1}$, respectively which are in excellent agreement with multiple studies ranging between 25 and 34 $\mathrm{kJ} \cdot \mathrm{mol}^{-1} \cdot{ }^{37-40}$ With all of the data collected in this work, better theoretical models for real world applications might be obtained: models that take molecular sieving, ${ }^{41}$ adsorption heat/energies, and molecular lattice vibrations into account. ${ }^{42}$

To finalize, all of the results presented in this work correspond to the characterization of a ZIF 8 SURMOF film, information highly relevant when considering its integration in thin film and coating technologies. Further measurements at temperatures above $100{ }^{\circ} \mathrm{C}$ were no longer conducted for the ZIF 8 SURMOF film studied in this work, as it could be observed that the mass deposited in the sensor started to decrease (ca. 5\%) during the $100{ }^{\circ} \mathrm{C}$ experiments. Likewise, its crystallinity and composition were also compromised. This provided an insight into the behavior of the material when exposed to noninert gases under harsh operation conditions. Long term experiments at the different pressure and temper ature conditions explored in this work are of high interest to obtain further information on the film's degradation limits. 


\section{CONCLUSIONS}

The adsorption of diverse gases at elevated temperatures and pressures on a ZIF 8 SURMOF film was investigated in this work via a crystal microbalance adapted for langatate sensors. Experimental findings for the ZIF 8 SURMOF film showed a preferential adsorption of the alkane over the alkene for the $\mathrm{C}_{2}$ hydrocarbons, while similar adsorption uptakes for the $\mathrm{C}_{3}$ hydrocarbons. The adsorption uptake in ZIF 8 increased with the hydrocarbon chain length, while the adsorption affinity for the alkane over the alkene was reduced as the chain length increased. In general, all of the single component adsorption isotherms could be described with the Langmuir model; future studies should focus on further improving the accuracy of the measurements, for example, by covering an even larger pressure range. The heats of adsorption obtained from these data when considering the low pressure region were of 18.1 and $19.5 \mathrm{~kJ} \cdot \mathrm{mol}^{-1}$ for $\mathrm{C}_{2} \mathrm{H}_{4}$ and $\mathrm{C}_{2} \mathrm{H}_{6}$ and of 29.1 and $31.2 \mathrm{~kJ}$. mol $^{-1}$ for $\mathrm{C}_{3} \mathrm{H}_{6}$ and $\mathrm{C}_{3} \mathrm{H}_{8}$, respectively. Significant variations in the adsorption uptake could also be noticed with increasing temperatures, which can be of particular interest for systems involving $\mathrm{C}_{2} \mathrm{H}_{6}$ and $\mathrm{C}_{2} \mathrm{H}_{4}$, considering the known preferential diffusion of $\mathrm{C}_{2} \mathrm{H}_{4}$ competing against the preferential adsorption of $\mathrm{C}_{2} \mathrm{H}_{6}$. Furthermore, a decrease in mass deposited could be observed during the measurements at $100{ }^{\circ} \mathrm{C}$, for which further experiments were not conducted.

Even though the collection of the experimental data over a wide range of conditions may not always be a trivial task, determining diverse parameters, such as saturation loadings and adsorption equilibrium constants, is fundamental for the creation and improvement of theoretical models. In the case of uptake measurements, the device used in this work proved as an attractive option for the deeper characterization of SURMOF films and other materials under harsh environments closer to those of real world applications. Additionally, the use of this device to study the long term stability of materials and the effect on its adsorption properties is highly interesting, particularly for new SURMOF structures with a demonstrated potential.

\section{AUTHOR INFORMATION}

\section{Corresponding Author}

Roland Dittmeyer - Institute for Micro Process Engineering (IMVT) and Institute of Catalysis Research and Technology (IKFT), Karlsruhe Institute of Technology (KIT), 76344 Eggenstein Leopoldshafen, Germany;

Email: roland.dittmeyer@kit.edu; Fax:+49721 60823186

\section{Authors}

Elvia P. Valadez Sánchez - Institute of Functional Interfaces (IFG) and Institute for Micro Process Engineering (IMVT), Karlsruhe Institute of Technology (KIT), 76344 Eggenstein Leopoldshafen, Germany
Alexander Knebel - Institute of Functional Interfaces (IFG), Karlsruhe Institute of Technology (KIT), 76344 Eggenstein Leopoldshafen, Germany;

Luis Izquierdo Sánchez - Institute for Micro Process Engineering (IMVT), Karlsruhe Institute of Technology (KIT), 76344 Eggenstein Leopoldshafen, Germany

Michael Klumpp - Institute for Micro Process Engineering (IMVT) and Institute of Catalysis Research and Technology (IKFT), Karlsruhe Institute of Technology (KIT), 76344 Eggenstein Leopoldshafen, Germany;

Christof Wöll - Institute of Functional Interfaces (IFG), Karlsruhe Institute of Technology (KIT), 76344 Eggenstein Leopoldshafen, Germany;

\section{Funding}

A.K. and C.W. are grateful for the funding from the DFG (German Science Foundation) within the SFB 1176 "Molecular Structuring of Soft Matter".

Notes

The authors declare no competing financial interest.

\section{ACKNOWLEDGMENTS}

A special thanks to the A. Terfort Group (University of Frankfurt) for providing us with perdeuterated hexadecane thiol used for IR background measurements.

\section{ABBREVIATIONS}

SURMOFs, surface mounted metal-organic framework; MOF, metal-organic framework; ZIF 8, zeolitic imidazolate framework 8; MUD, 11 mercapto 1 undecanol; SAM, self assembled monolayer; LBL, layer by layer; LPE, liquid phase epitaxy; XRD, X ray diffraction; IRRAS, infrared reflection absorption spectroscopy; MCT, mercury cadmium telluride; SEM, scanning electron microscopy; EDXS, EDXM, energy dispersive $\mathrm{X}$ ray spectroscopy and mapping; eQCM, electro chemical quartz crystal microbalance; LCM, langatate crystal microbalance

\section{REFERENCES}

(1) Heinke, L.; Tu, M.; Wannapaiboon, S.; Fischer, R. A.; Wöll, C. Surface mounted metal organic frameworks for applications in sensing and separation. Microporous Mesoporous Mater. 2015, 216, 200-215.

(2) Zhuang, J. L.; Terfort, A.; Wöll, C. Formation of oriented and patterned films of metal-organic frameworks by liquid phase epitaxy: A review. Coord. Chem. Rev. 2016, 307, 391-424.

(3) Bétard, A.; Fischer, R. A. Metal-organic framework thin films: from fundamentals to applications. Chem. Rev. 2011, 112, 10551083.

(4) Zacher, D.; Schmid, R.; Wöll, C.; Fischer, R. A. Surface chemistry of metal-organic frameworks at the liquid-solid interface. Angew. Chem., Int. Ed. 2011, 50, 176-199.

(5) Allendorf, M. D.; Houk, R. J. T.; Andruszkiewicz, L.; Talin, A. A.; Pikarsky, J.; Choudhury, A.; Gall, K. A.; Hesketh, P. J. Stress Induced Chemical Detection Using Flexible Metal-Organic Frameworks. J. Am. Chem. Soc. 2008, 130, 14404-14405.

(6) Tsionsky, V.; Gileadi, E. Use of the quartz crystal microbalance for the study of adsorption from the gas phase. Langmuir 1994, 10, 2830-2835.

(7) Davulis, P. M.; Da Cunha, M. P. High temperature langatate elastic constants and experimental validation up to $900{ }^{\circ} \mathrm{C}$. IEEE Trans. Ultrason. Ferroelectr. Freq. Control 2010, 57, 59-65. 
(8) Ding, W.; Klumpp, M.; Li, H.; Schygulla, U.; Pfeifer, P.; Schwieger, W.; Haas Santo, K.; Dittmeyer, R. Investigation of high temperature and high pressure gas adsorption in zeolite $\mathrm{H}$ ZSM 5 via the langatate crystal microbalance: $\mathrm{CO}_{2}, \mathrm{H}_{2} \mathrm{O}$, methanol, and dimethyl ether. J. Phys. Chem. C 2015, 119, 23478-23485.

(9) Park, K. S.; Ni, Z.; Côté, A. P.; Choi, J. Y.; Huang, R.; Uribe Romo, F. J.; Chae, H. K.; O’Keeffe, M.; Yaghi, O. M. Exceptional chemical and thermal stability of zeolitic imidazolate frameworks. Proc. Natl. Acad. Sci. U.S.A. 2006, 103, 10186-10191.

(10) Lee, Y. R.; Jang, M. S.; Cho, H. Y.; Kwon, H. J.; Kim, S.; Ahn, W. S. ZIF 8: A comparison of synthesis methods. Chem. Eng. J. 2015, 271, 276-280.

(11) Rungta, M.; Zhang, C.; Koros, W. J.; Xu, L. Membrane based ethylene/ethane separation: The upper bound and beyond. AIChE J. 2013, 59, 3475-3489.

(12) Bux, H.; Chmelik, C.; Krishna, R.; Caro, J. Ethene/ethane separation by the MOF membrane ZIF 8: molecular correlation of permeation, adsorption, diffusion. J. Membr. Sci. 2011, 369, 284-289.

(13) Valadez Sánchez, E. P.; Gliemann, H.; Haas Santo, K.; Ding, W.; Hansjosten, E.; Wohlgemuth, J.; Wöll, C.; Dittmeyer, R. $\alpha \mathrm{Al}_{2} \mathrm{O}_{3}$ supported ZIF 8 SURMOF membranes: Diffusion mechanism of ethene/ethane mixtures and gas separation performance. J. Membr. Sci. 2020, 594, 117421 .

(14) Benali, M.; Aydin, B. Ethane/ethylene and propane/propylene separation in hybrid membrane distillation systems: Optimization and economic analysis. Sep. Purif. Technol. 2010, 73, 377-390.

(15) Míguez, J.; Porteiro, J.; Pérez Orozco, R.; Gómez, M. Technology Evolution in Membrane Based CCS. Energies 2018, 11, 3153

(16) Valadez Sánchez, E. P.; Gliemann, H.; Haas Santo, K.; Wöll, C.; Dittmeyer, R. ZIF 8 SURMOF Membranes Synthesized by $\mathrm{Au}$ Assisted Liquid Phase Epitaxy for Application in Gas Separation. Chem. Ing. Tech. 2016, 88, 1798-1805.

(17) Valadez Sánchez, E. P. Thin Film MOFs (SURMOFs) for Application in Gas Separation; KIT Scientific Publishing, 2019.

(18) Ding, W.; Baracchini, G.; Klumpp, M.; Schwieger, W.; Dittmeyer, R. Adsorption Device Based on a Langatate Crystal Microbalance for High Temperature High Pressure Gas Adsorption in Zeolite H ZSM 5. J. Visualized Exp. 2016, No. e54413.

(19) Tsionsky, V.; Daikhin, L.; Urbakh, M.; Gileadi, E. Behavior of quartz crystal microbalance in nonadsorbed gases at high pressures. Langmuir 1995, 11, 674-678.

(20) Sauerbrey, G. Verwendung von Schwingquarzen zur Wägung dünner Schichten und zur Mikrowägung. Z. Phys. 1959, 155, 206222

(21) Ding, W. Simulation Assisted Design of Polycrystalline Zeolite Catalysts; KIT Scientific Publishing, 2016.

(22) Shekhah, O.; Swaidan, R.; Belmabkhout, Y.; Du Plessis, M.; Jacobs, T.; Barbour, L. J.; Pinnau, I.; Eddaoudi, M. The liquid phase epitaxy approach for the successful construction of ultra thin and defect free ZIF 8 membranes: pure and mixed gas transport study. Chem. Commun. 2014, 50, 2089-2092.

(23) Böhme, U.; Barth, B.; Paula, C.; Kuhnt, A.; Schwieger, W.; Mundstock, A.; Caro, J.; Hartmann, M. Ethene/ethane and propene/ propane separation via the olefin and paraffin selective metal organic framework adsorbents CPO 27 and ZIF 8. Langmuir 2013, 29, 85928600

(24) Su, W.; Zhang, A.; Sun, Y.; Ran, M.; Wang, X. Adsorption Properties of $\mathrm{C} 2 \mathrm{H} 4$ and $\mathrm{C} 3 \mathrm{H} 6$ on 11 Adsorbents. J. Chem. Eng. Data 2016, 62, 417-421.

(25) Pimentel, B. R.; Lively, R. P. Enabling kinetic light hydrocarbon separation via crystal size engineering of ZIF 8. Ind. Eng. Chem. Res. 2016, 55, 12467-12476.

(26) James, J. B.; Wang, J.; Meng, L.; Lin, Y. S. ZIF 8 membrane ethylene/ethane transport characteristics in single and binary gas mixtures. Ind. Eng. Chem. Res. 2017, 56, 7567-7575.

(27) Chmelik, C.; Freude, D.; Bux, H.; Haase, J. Ethene/ethane mixture diffusion in the MOF sieve ZIF 8 studied by MAS PFG NMR diffusometry. Microporous Mesoporous Mater. 2012, 147, 135-141.
(28) Wu, H.; Zhou, W.; Yildirim, T. Methane Sorption in Nanoporous Metal-Organic Frameworks and First Order Phase Transition of Confined Methane. J. Phys. Chem. C 2009, 113, 30293035.

(29) Zhou, M.; Wang, Q.; Zhang, L.; Liu, Y. C.; Kang, Y. Adsorption sites of hydrogen in zeolitic imidazolate frameworks. J. Phys. Chem. B 2009, 113, 11049-11053.

(30) Ruthven, D. M. Principles of Adsorption and Adsorption Processes; John Wiley \& Sons, 1984.

(31) Krokidas, P.; Castier, M.; Economou, I. G. Computational study of ZIF 8 and ZIF 67 performance for separation of gas mixtures. J. Phys. Chem. C 2017, 121, 17999-18011.

(32) Wu, Y.; Chen, H.; Liu, D.; Qian, Y.; Xi, H. Adsorption and separation of ethane/ethylene on ZIFs with various topologies: Combining GCMC simulation with the ideal adsorbed solution theory (IAST). Chem. Eng. Sci. 2015, 124, 144-153.

(33) Zhang, C.; Lively, R. P.; Zhang, K.; Johnson, J. R.; Karvan, O.; Koros, W. J. Unexpected molecular sieving properties of zeolitic imidazolate framework 8. J. Phys. Chem. Lett. 2012, 3, 2130-2134.

(34) Liu, D.; Wu, Y.; Xia, Q.; Li, Z.; Xi, H. Experimental and molecular simulation studies of $\mathrm{CO}_{2}$ adsorption on zeolitic imidazolate frameworks: ZIF 8 and amine modified ZIF 8. Adsorption 2013, 19, 25-37.

(35) Herm, Z. R.; Bloch, E. D.; Long, J. R. Hydrocarbon Separations in Metal-Organic Frameworks. Chem. Mater. 2014, 26, 323-338.

(36) Zhang, L.; Li, Q.; Lu, Z.; Wang, X. Understanding Adsorption and Separation behavior of shorter chain alkane mixtures in Zeolitic Imidazolate Frameworks by molecular simulations. Procedia Comput Sci. 2011, 4, 1193-1202.

(37) Krokidas, P.; Castier, M.; Moncho, S.; Brothers, E.; Economou, I. G. Molecular simulation studies of the diffusion of methane, ethane, propane, and propylene in ZIF 8. J. Phys. Chem. C 2015, 119, 2702827037.

(38) Liu, D.; Ma, X.; Xi, H.; Lin, Y. S. Gas transport properties and propylene/propane separation characteristics of ZIF 8 membranes. $J$ Membr. Sci. 2014, 451, 85-93.

(39) Hara, N.; Yoshimune, M.; Negishi, H.; Haraya, K.; Hara, S. Yamaguchi, T. Diffusive separation of propylene/propane with ZIF 8 membranes. J. Membr. Sci. 2014, 450, 215-223.

(40) Li, K.; Olson, D. H.; Seidel, J.; Emge, T. J.; Gong, H.; Zeng, H.; $\mathrm{Li}$, J. Zeolitic imidazolate frameworks for kinetic separation of propane and propene. J. Am. Chem. Soc. 2009, 131, 10368-10369.

(41) Zheng, B.; Pan, Y.; Lai, Z.; Huang, K. W. Molecular dynamics simulations on gate opening in ZIF 8: identification of factors for ethane and propane separation. Langmuir 2013, 29, 8865-8872.

(42) Knebel, A.; Geppert, B.; Volgmann, K.; Kolokolov, D. I.; Stepanov, A. G.; Twiefel, J.; Heitjans, P.; Volkmer, D.; Caro, J. Defibrillation of soft porous metal organic frameworks with electric fields. Science 2017, 358, 347-351. 
Karlsruher Institut für Technologie

\section{Repository KITopen}

Dies ist ein Postprint/begutachtetes Manuskript.

Empfohlene Zitierung:

Valadez Sánchez, E. P.; Knebel, A.; Izquierdo Sánchez, L.; Klumpp, M.; Wöll, C.; Dittmeyer, R.

Studying ZIF-8 SURMOF Thin Films with a Langatate Crystal Microbalance: SingleComponent Gas Adsorption Isotherms Measured at Elevated Temperatures and Pressures. 2020. Langmuir, 36

doi:10.5445/IR/1000121916

Zitierung der Originalveröffentlichung:

Valadez Sánchez, E. P.; Knebel, A.; Izquierdo Sánchez, L.; Klumpp, M.; Wöll, C.; Dittmeyer, R.

Studying ZIF-8 SURMOF Thin Films with a Langatate Crystal Microbalance: SingleComponent Gas Adsorption Isotherms Measured at Elevated Temperatures and Pressures. 2020. Langmuir, 36 (29), 8444-8450.

doi:10.1021/acs.langmuir.0c00875 